\title{
The Academic System for Studying Public Administration in the Kingdom of Saudi Arabia: \\ A Comparative Study
}

\author{
Mishaal Obied Alrasheed \\ Student of the Doctor of Public Administration \\ King Saud University \\ Kingdom of Saudi Arabia \\ alrasheedmishaal3@gmail.com
}

\begin{abstract}
The study aims to identify the academic system for studying public administration in the Kingdom of Saudi Arabia and compare it with the United States of America. The comparative approach was followed by preparing the comparison card, which dealt with the similarities and differences about the academic system in the study of public administration in the Kingdom of Saudi Arabia and the United States of America. The study was applied to the academic system in teaching public administration in the Kingdom of Saudi Arabia and compared to the United States of America. The study showed the most important differences between the two universities in the teaching of public administration, the most prominent of which was that universities in the Kingdom of Saudi Arabia focus on the theoretical side of public administration, unlike universities in the United States of America, which focus on the student deepening in the specialization applied more than theoretically. The conditions for student admission to a master's program differ in both countries, and doctoral programs in public administration in universities in the Kingdom of Saudi Arabia focus on teaching human resources management courses in the public sector, health management, and public financial management, while in the United States of America they focus on teaching The fields of environmental policy, international economic policy, decision sciences, science and technology, international security relations, risk assessment and policy for economic regulation, international development, governance, and decision-making. With the students' needs, goals, and previous experiences, and providing financial support to public administration programs, provide them with academic expertise, cooperating with advanced universities, and trying to benefit from their experiences in teaching.
\end{abstract}

Keywords: The Academic System, Teaching Public Administration, Kingdom of Saudi Arabia.

\section{Introduction}

In all the eras that humanity has gone through, the university is a symbol of the renaissance of nations and a title for their greatness and sophistication, and a social and civilizational necessity dictated by the requirements of the times as the entity that embraces the cultural environment with its intellectual, scientific and technological dimensions, and represents the community's mind and human conscience in facing challenges and changes at the cultural and intellectual level and the community's eye in its vision And his aspirations towards the future, inspired by his heritage and civilized personality. The development of nations is often measured in light of the position of their educational institutions, especially universities, as the scientific environments qualified to supply state and society institutions with efficient human resources capable of achieving progress

\footnotetext{
* This article was submitted in August 2021, and accepted for publishing in September 2021.

(c) Arab Administrative Development Organization- League of Arab States, 2022, pp 395-406، D DOI: 10.21608/aja.2021.92282.1145
} 
in all fields of life. In its contemporary concept, the university is a factory of knowledge, and its goals will no longer be a societal luxury to prepare human resources and give them certificates in different specializations to fill jobs in the labor market. Rather, it has become a strategic choice within the framework of an investment and development system for human resources.

Public administration is considered one of the most important pillars of building public institutions that connect society and its members with a social contract with the aim of providing public services in all fields. The idea of public administration depends on empowering the citizen and giving him authority and handing over the helm of leadership to pioneers in order to achieve a specific mission and encourage competition, decentralization, overall quality, reducing red tape, and reforming The civil service and privatization also, which is the management of the affairs of institutions that manage the lives of a group of people within a specific geographical and political scope, and this administration expresses the needs of the people and raises their demands and hopes and works to achieve their aspirations. (Ocoin, 2008)

During the past decade, a large segment of Arab academics in universities paid great attention to teaching public administration and public policies in Middle Eastern universities, and the interest was not limited to developing programs and departments concerned with teaching public administration only, but efforts were focused towards researching these multiple policies at all levels and in all countries. (Alijla, 2019). The concept of public administration refers to all the operations that aim to implement and contribute to the policies and programs of the government sector or the public sector, with the aim of implementing the necessary administrative operations such as planning, organizing, directing, and coordinating, in addition to monitoring and follow-up, where this activity can be practiced on many levels, including the central, middle, or local level (Al-Maghribi, 2008), as it refers to a set of organization and coordination strategies that will achieve the planned and specific goals by optimizing the use of available resources such as capital, technology, and natural resources, And human resources, whose management is one of the most important functions of a public administration specialty. (Al-Nimer et al., 2013)

The case of Western countries in the field of public administration study represents a rich scientific model worthy of study and attention, as Western schools, institutes and specialized colleges, whether in the field of administrative sciences or specialized in the field of social sciences in general, such as political sciences, law, economics, psychology and sociology - all played an important role in Laying the foundations of the field and recognizing it as a specialized and independent field in the study of issues of public affairs management, public policies and the governmental sector, in conjunction with the contributions of American schools over time and previous decades of the field's life, despite the fact that the call to establish a science of public administration is an American call of origin mainly by the scientist The great (Woodrow Wilson 1887 AD), in addition to the contributions of Western public administration schools to the development of the field, especially the contributions and ideas of the famous German sociologist Max Weber and his studies on bureaucracy and patterns of power, the studies of the French Henri Fayol on administrative divisions and others, and the efforts of the German economist Stanz Vaughn Some see him as the actual founder of the field of public administration in Europe, along with Spain Contemporary Importance of Schools in Western European Countries (English, German, French). (Katarina \& Gyorgy, 2016)

The Department of Public Administration is one of the leading university departments in the Kingdom of Saudi Arabia, which is very popular among students, as evidenced by the large number of applicants to public administration programs and the necessity of universities to set up a system for differentiation and admission, due to the large number of applicants who seek to study it, given the great benefit of this branch, and for providing it as A large number of job opportunities, which is based on efficiency and effectiveness, through which it aims to reach the desired goal with the least effort possible, using the lowest costs and the fastest methods, and understanding how to manage public sectors more than understanding the management of private sectors, increasing the skills of students and employees, and encouraging them to Managing their organizations 
effectively and practically, and with scientific efficiency, and in view of the excellence shown by European and American countries in the field of public administration study. In the Kingdom of Saudi Arabia, public administration is studied in most universities due to its importance in raising the efficiency and level of graduates and raising their ability to effectively manage and formulate and implement public policies. Hence the need to study the academic system in the study of public administration in the Kingdom of Saudi Arabia and compare it with the state The United States of America to find out the most prominent similarities and differences between both, the reasons for the difference and its justifications, and to provide appropriate recommendations about the Saudi academic system.

\section{Previous Studies}

The study of (Awaah et al., 2021) aimed to identify on empirical evidences of students lived experiences of what they consider difficult in the study of PA in Ghana and Nigeria; establishing relations between selected variables and perceived difficulties Using a quantitative approach and sample $N 1 / 4650$, The study concludes that, African university students not having previous backgrounds in PA and syllabus being too wide accounts for difficulties in the study of PA; there is a statistically significant difference regarding bureaucracy, ethics, corruption, and arms of government between lower levels and upper level African university students on the perceived difficulty in the study of PA and there is a statistically significant difference between Bachelor of Business Administration and Bachelor of Science Public Administration among African university students in all concepts observed except government, public policy, politics and defining PA. We suggest teaching PA is remodeled as a study of classroom training those places students understanding at its core.

The study of (Azizuddin \& Hossain, 2021) aims to review public administration education in the higher education institutions in Bangladesh, and their role in ensuring modern public services. Most universities in the country offer public administration degrees; however, minimal contributions to nation building have been observed, this is a qualitative study with gleaned data, using inductive content analysis to investigate the phenomenon with three case universities indicating the link between curriculum and learning delivery at the universities in Bangladesh. The research finds that poor development-oriented public administration education has little correlation to national development. The education system is traditional, where typical cultural features are nonchalance and indifference towards domestic demands. The discipline cannot create a distinctive identity and position in academia, which has consequences for the advancement of the administrative system in a developing country like Bangladesh. A research-informed curriculum with innovative pedagogical approach might be an alternative. The paper enlightens both academics and practitioners, as literature on public administration education in Bangladesh has been scarce. It calls for higher education institutions to reassess public administration education, teaching methods and research for national development.

The study of (Alijla, 2019) aimed to examines the challenges facing PA education, considering the colonial heritage of the region. Over the past decade, researchers have paid attention to Public Administration (PA) and its education in the Middle East. Many explored the history of the PA in the region and the quality of PA programs within high education institutes. In the context of the developmental challenges that face the current generation in the region, and under the current political circumstances which have negative consequences on PA, many voices call for a reliable and high-quality PA education and good governance, which includes accountability, transparency, democracy, and other concepts related to bureaucratic machinery within the public institutions. There is therefore a need to examine what governmental institutions, together with academic institutions in the Arab States, are doing to make significant progress in this field. The paper examines the main challenges facing PA education in Arab countries

The study of (Al-Arabi, 2018) aimed to identify some of the most important features of the academic system for studying the specialization of public administration in European countries with the aim of becoming familiar with the general academic trends in this important part of the Western world where its contribu- 
tions to the field are similar to the American schools of public administration, where the study clarified some of the prevailing features In the schools and universities of Eastern and Central European countries, Western European countries (the English, French, and German schools), the models of North and South European countries, the study showed that the European experience is rich not only at the level of administrative practices in government agencies, but also at the level of the theoretical academic field, Where the great diversity in the practice aspect had its impact on the diversity of the study programs concerned with the study of public administration, despite this, many European institutions, unions and schools made many efforts in order to reach the design of study programs bearing a purely European character in line with the spirit of the Union and its experience in regional integration on various Institutional levels, whether political, economic or social, and for that matter, the study viewed some of the institutional efforts exerted in order to develop a unified vision for the study of public administration from a European perspective, with an indication of some of the driving and enhancing factors for this trend and the difficulties and problems facing it, as well as some areas of research renewal in the field of contemporary European thought for the study of public administration.

The study of (Marleen \& Laurien, 2016) which discussed the absence of a unified pattern for public administration study programs in European universities, and that the European academic system has suffered from this difficulty for more than 25 years, despite the joint coordinated efforts among the countries of the Union to improve and bridge the gaps in education policies. The study also dealt with some European institutional efforts in order to contain this gap to bring European schools closer to the features of a unified project for public administration study programs in Europe, especially the SOCRATES - ERASMUS project, and the European Network for Public Administration.

The study of (Draa, 2016) aimed to identify the presence of the development of public administration between the past and the present and to present the most important contributions of thinkers and their effects on public administration. And many challenges had effects on public administration, the most important of which are the different role of the state, environmental changes, the development of information and communication technology, and globalization.

The study of (Van der Waldt, 2014) aimed to intends to reflect on the potential consequences, both positive and negative, that interdisciplinary studies have on the teaching of Public Administration. The article will review the possible advantages or contributions of interdisciplinary to the teaching of Public Administration, and reflect on the possibly less-desired consequences of interdisciplinary collaboration on curriculum design and teaching methods, The value of interdisciplinary should be evident from the arguments to prepare students for the world of governance, Public Administration curricula should reflect the need to recognize the contributions of integrative studies.

\section{Commenting on Previous Studies}

After reviewing previous Arab and foreign studies on the subject, the researcher concluded that the majority of the studies dealt with the study of public administration and that the majority of the studies are relatively recent, having been conducted from 2014 to 2021, and the places of application of the studies varied, in addition to the fact that the majority of studies adopted the descriptive-analytical approach and the method Comparative.

This study has benefited from previous studies by enriching the theoretical literature related to the academic system in the study of public administration in the Kingdom of Saudi Arabia: a comparative study, and helping to benefit from previous studies in determining the appropriate study approach, formulating the study problem and the type of statistical treatment used.

What distinguishes this study from other previous studies is that it falls within the first studies that will discuss the academic system in the study of public administration in the Kingdom of Saudi Arabia: a comparative study, which was conducted in the Kingdom of Saudi Arabia. 


\section{The Study Problem}

American and European thought has contributed to the development of public administration science as an independent scientific discipline and has academic study programs in all countries of the world, especially in the Kingdom of Saudi Arabia, as the education system is undergoing a permanent review, especially in light of the Kingdom's vision 2030 with the aim of developing it to meet the requirements of the vision and to be able to compete in the field of economy Knowledge, and the Kingdom's vision 2030 focused on developing the educational system with all its components and providing students with the knowledge and skills necessary for success in the future. Therefore, the education file occupied a large space in the Kingdom's vision document, one of its most prominent goals is to harmonize the outputs of the educational system with the needs of the labor market, and from here came The idea of the study in which the researcher is interested in studying the academic system to study the specialization of public administration in the American case with standing on some points and stations of renewal in field studies with American academic entities in terms of future projects, research ideas and new practice issues that occupy the thought of professors, pioneers, European researchers and centers of thought and opinion, and compare them The Academic System of Public Administration in the Kingdom of Saudi Arabia In Saudi Arabia, where the problem of the study centers on answering the following two questions:

- What is the academic system for studying public administration in the Kingdom of Saudi Arabia?

- What is the academic system for studying public administration in the United States of America?

- What are the main points of similarity and difference between the academic system in the study of public administration in the Kingdom of Saudi Arabia and the United States of America?

\section{The Study Objectives}

The study aims to achieve the following objectives:

- $\quad$ Familiarization with the academic system for studying.

- Identify the most prominent similarities and differences between the academic system in the study of public administration in the Kingdom of Saudi Arabia and the United States of America, and the reasons for the difference and its justifications.

- Provide appropriate recommendations about the Saudi academic system through the findings of the study.

\section{The Importance of Study}

The importance of the study lies in the importance of the topic that will be addressed, which is the academic system in the study of public administration in the Kingdom of Saudi Arabia and the United States of America as a comparative study, and its importance is summarized in the following points:

- Providing feedback that benefits the educational systems in neighboring countries, in addition to helping and motivating decision-makers to take appropriate measures to improve the academic system for studying public administration.

- In addition, its importance emerges from the fact that it is a few studies within the limits of the researcher's knowledge that will address the features of the academic system in the study of public administration in the Kingdom of Saudi Arabia and the United States of America as a comparative study. The Kingdom of Saudi Arabia and its comparison with the United States of America.

- The study may form an important link in the field of academic systems, and a starting point for many researchers to conduct similar subsequent studies. 


\section{Study Methodology}

According to the nature of the research problem and its questions, the comparative approach will be used to reach the results of the study, according to the following steps:

1- Description: This step includes collecting data, information, and educational data about the academic system in the study of public administration in the country of study by reviewing previous studies.

2- Analysis and interpretation: This step includes analyzing the reality of the academic system in the study of public administration in the countries' understudy in the light of the forces and factors affecting it.

3- The debate: This step aims to reach points of similarity and difference between the Kingdom of Saudi Arabia and the United States of America regarding the academic system in the study of public administration.

4- Comparison: In this step, the validity of the real hypothesis of the research is verified and the similarities and differences are explained.

\section{The Study Population and Sample}

The study was applied to the academic system in the study of public administration in the Kingdom of Saudi Arabia and the United States of America by referring to previous studies related to the subject, and the academic system for teaching public administration in the Kingdom of Saudi Arabia has been compared with the academic system in the United States of America.

\section{Study Tool and its Validity}

A comparison card was prepared, which dealt with the similarities and differences about the academic system in the study of public administration in the Kingdom of Saudi Arabia and the United States of America, and it was presented to a group of arbitrators to determine its suitability and suitability to the study problem and questions.

\section{Results}

This part includes a presentation and analysis of the study results, which are as follows:

\section{Results of the first question: What is the academic system in the study of public administration in the Kingdom of Saudi Arabia?}

After my review of many previous studies related to the subject of public administration and my review of study plans and academic programs in teaching public administration specialization in the Kingdom of Saudi Arabia, I found the following:

- Saudi universities are interested in the practical application of the specialization, but they are more interested in the theoretical aspect of public administration so that the student graduates either as a researcher in public administration without practical experience or holds a public administration certificate without practical tools.

- The public administration major is taught as a bachelor's program in most Saudi universities under the name of an independent academic program in "administrative sciences" with a total of (132) credit hours. in society by providing the opportunity for faculty members to benefit from the capabilities of infrastructure and practical research, and finding link points between comprehensive development in society and the program through the consolidation of the concept of administrative development in society. 
- The master's program in public administration is also taught to prepare and qualify human cadres and provide them with different knowledge and administrative skills, according to multiple tracks such as local administration, administrative leadership, human resources, and public finance, in most Saudi universities.

- In all universities, in order for the student to join the master's program, he must have a field close to the specialization of public administration, and priority is given to graduates of political science and economics from a recognized university. He must have obtained a minimum score of (70) in the general aptitude test for university students, obtained a score of no less than (45) in the TOEFL-IBT test or its equivalent within the past two years, and passed the personal interview and the tests set by the university.

- At King Saud University, a Master of Public Administration is taught at a rate of (42) hours, with a grade of no less than "very good", as follows: (30) hours of compulsory courses, (9) hours of specialization courses, and (3) hours of elective courses, and the tracks The specialization taught in the program and these tracks are taught in Arabic, and they are as follows: leadership and strategic management track, human resources management track, public policies and budget track, non-profit organizations track, local administration track), and the university also has an executive master's in governance and public policies As an independent program, it is taught by (39) credits of master's courses, and for the subjects to be taught: (public administration between theory and practice, human resource management, organizational behavior, quantitative analysis in public administration, scientific research methods, information management and decision support, finance and budget public service, organizational development, public service ethics, and a research project) in addition to elective courses.

- At King Abdulaziz University, to obtain a master's degree in public administration, the student must complete at least (36) credits, and the subjects to be taught: (public administration theory, scientific research methods in public administration, human behavior in public organizations, Islamic ethics in public administration, the general budget, computer applications in public organizations) in addition to elective courses and thesis.

- Master's programs in Public Administration in the Kingdom of Saudi Arabia aim to qualify public administration cadres capable of managing public organizations effectively and efficiently, enhancing public administrative knowledge through serious academic research programs, providing practical solutions to local administrative issues and obstacles, and building and strengthening strategic partnership by providing Consulting services to organizations in the public and non-profit sectors, partnering with professional organizations, and other public departments, and contributing to the professional development of public servants in the public and non-profit sectors for advancement in their agencies.

- As for the doctoral program in public administration, it is taught at King Saud University under the name: Doctor of Philosophy Program in Public Administration. To obtain the degree, the student must pass (36) hours of study divided as follows: (21) units in basic general courses, and (15) One unit in the specialized courses. As for the specialized tracks in the program, it includes human resources management in the public sector, health management, public financial management.

- Ph.D. programs in public administration aim to meet the needs of the public sector in the Kingdom of Saudi Arabia for specialized cadres in the field of management capable of transferring and localizing knowledge and management technology. It also aims to raise the level of public service academically and professionally. It also aims to graduate highly qualified specialists in the field of conducting administrative research and teaching in academic institutions and providing management consultancy to public organizations. 
- As for the language in which public administration teaching programs are taught, after reviewing the study plans for the undergraduate, master's, and doctoral academic programs, it became clear to me that they are taught in Arabic.

- Most of the Saudi universities depend on a literal evaluation system, the greatest degree in which is $(A+)$ and the failing grade is $(E)$ or two numerical evaluation systems ranging from 5 as an upper grade and 1 as a failing grade.

- The courses taught in Saudi universities are a mixture of public administration teaching programs in the United States, Britain, and France and do not address government administrative phenomena such as corruption and do not focus on the form of public administration in governments and their management in the region. Diversity management, management ethics, anti-corruption materials, and transparency, are among the most important requirements of the stage and public administration in the region.

- As for the costs of studying bachelor's, master's, and doctoral programs in the United States of America, it varies from one university to another.

\section{The results of the second question: What is the academic system in the study of public administra- tion in the United States of America?}

After my review of the academic programs in American universities that study public administration, and these universities are Harvard University, New York University, and Stanford University, as these universities are distinguished by the excellence of their academic programs at the world level, and after my review of the theoretical literature and previous studies related to the subject, I found the following:

- As for the Bachelor's Program in Public Administration in the United States of America, it was designed to provide professional preparation for public sector managers. It is taught in most American universities with a rate of (132) credit hours, including compulsory requirements, specialization requirements, and optional requirements in addition to the graduation requirement. The study takes four years.

- As for the master's program in public administration, it is taught in most American universities, and the duration of study is (5) semesters. The master's program in public administration includes many courses in the fields of leadership, management, political thought, institutional building, public policy, and economics, and it includes some Masters in Public Administration programs are courses in economics to give students a background in microeconomic issues (markets, rationing mechanisms, etc.) and macroeconomic issues (such as the national debt).

- To join the Master's Program in Public Administration in the United States of America, the student must have a bachelor's degree from an internationally recognized university, and it must be related to the major in public administration, and the language test certificates must be passed according to the following assessments (IELTS certificate with a total of (7)). Minimum grades or more, and TOEFL certificate with a minimum score of 90)

- With regard to the doctoral program in public administration in the United States of America, a program has been designed to prepare students for leading positions in teaching, research, and public service. and risk assessment and policy for economic regulation, international development, and governance and decision-making, and completion of a doctoral program typically requires two years of work and two more years of the thesis.

- American universities rely on the English language in teaching courses for academic programs for teaching public administration. 
- Most American universities also rely on a literal evaluation system, with the highest-grade being $A$, and the failing grade being $F$, or two numerical evaluation systems ranging from 5 as an upper grade and 1 as a failing grade.

- As for the costs of studying bachelor's, master's, and doctoral programs in the United States of America, it varies from one university to another, as it ranges in total between 12000 and 35000 US dollars.

\section{The results of the third question: What are the main points of similarity and difference between the academic system in the study of public administration in the Kingdom of Saudi Arabia and the Unit- ed States of America?}

After reviewing many of the available previous studies on the subject and studying them in-depth, the similarities and differences in the academic system in the study of public administration in the Kingdom of Saudi Arabia and the United States of America were clarified, as follows:

- The first axis: similarities in the academic system in the study of public administration in the Kingdom of Saudi Arabia and the United States of America.

After I studied the academic system for teaching public administration in the Kingdom of Saudi Arabia and the academic system in the United States of America, I reached points of similarity between both countries in the system of teaching academic public administration programs, which are summarized in the following:

- A bachelor's degree in public administration is taught in both countries at a rate of (132) credit hours distributed over four academic years.

- In the master's program, the student must have a bachelor's degree from a recognized university and be related to the public administration specialization.

- The duration of study for the master's and doctoral programs is similar, which is two academic years for the master's program, and for the doctoral program is (4) years, which includes the thesis.

- The second axis: the differences in the academic system in the study of public administration in the Kingdom of Saudi Arabia and the United States of America.

After reviewing the academic systems in the Kingdom of Saudi Arabia and the United States of America with regard to public administration teaching programs, and after in-depth research in them, I reached many points of difference between the two countries, which I summarized in the following:

- Universities in the Kingdom of Saudi Arabia focus on the theoretical side of public administration, unlike universities in the United States of America, which focus on the student deepening the specialization in practice rather than theory.

- Doctoral programs in public administration in universities in Saudi Arabia focus on teaching human resources management courses in the public sector, health administration, and public financial management, while in the United States of America they focus on teaching the areas of environmental policy, international economic policy, decision sciences, science and technology, and security relations International risk assessment and policy for economic regulation, international development, governance, and decision-making.

- American universities rely on the English language in teaching the courses of the academic programs for teaching public administration, while in the Kingdom of Saudi Arabia they are taught in the Arabic language.

- The cost of studying in the United States of America is higher than the cost of studying in the Kingdom of Saudi Arabia in all academic programs for teaching public administration. 


\section{Recommendations}

In light of the results of the study, the researcher recommends the following:

- The need to enhance the practical application in public administration education, with a focus on developing curricula and teaching methods in a way that suits students' needs, goals, and previous experiences.

- Providing financial support to public administration programs and providing them with academic expertise, cooperating with the universities provided, and trying to benefit from their teaching experiences.

- Providing training opportunities for students studying in the field of public administration to improve their ability to understand the methods and methods of public administration and its problems and how to find solutions to them.

- That universities, through colleges, cooperate and coordinate with the deanships of scientific research to enhance interaction and partnership with state institutions and the private sector in order to contribute to the support and development of the public administration specialization, in order to provide opportunities for faculty members and students of public administration majors to address real problems that these institutions suffer from and to employ methodologies scientific treatment.

- Conducting more studies and research related to the academic system to study public administration in other universities.

\section{The Limits of the Study}

The results of the current study are determined in the light of the following limitations:

- Objective Limits: The study will be limited to identifying the academic system in the study of public administration in the Kingdom of Saudi Arabia and the United States of America as a comparative study.

- Spatial Limits: the current research will be limited to addressing the features of the academic system in the Kingdom of Saudi Arabia and the United States of America.

- Time Limits: The study will be conducted in the second semester of the year 2021 AD. 


\section{References:}

- $\quad$ Al-Arabi, Muhammad. (2018). "Features of the academic mother to study public administration in Europe", Journal of the Faculty of Economics and Political Science, Cairo University, Vol. 19 (3), pp. 193-230.

- $\quad$ Al-Nimr, Saud. (2013). Public Administration: Foundations, Functions and Modern Trends. $7^{\text {th }}$ ed., Al Shukri Library, Kingdom of Saudi Arabia.

- $\quad$ Alijla, Abdalhadi M. (2019) "From Practices to Teaching: Challenges and Opportunities of Public Administration in the Arab World," International Journal for Research in Education, Vol. 43: Iss. 3, Article 3. Available at: https://scholarworks.uaeu.ac.ae/ijre/vol43/iss3/3.

- Aucoin, Peter. (2008). "New Public Administration and Government Quality: Dealing with the New Political Administration in Canada", Conference on New Public Administration and Government Quality, SOG and Government Quality, University of Gothenburg, Sweden, 13-15 November.

- $\quad$ Awaah, F.; Okebukola, P.; Alfa, A.; Yeboah, S.; Anagba, K. \& Arkorful, H. (2021). “Developing Public Administration Education by Focusing on Difficult Key Concepts: The Case of Nigeria and Ghana", Social Sciences \& Humanities Open, (4), pp. 1-7.

- $\quad$ Azizuddin, Muhammad \& Hossain, Akram. (2021). “Reflections on Public Administration Education with a Case of Bangladesh", Teaching Public Administration. Vol. 39, (1), pp. 46-66.

- Brans, Marleen \& Laurien Coenen. (2016). “The Europeanization of Public Administration Teaching", Policy and Society, Vol. 35, 4, pp. 333-349.

- Draa, Munira. (2016). "Intellectual Implications of Public Administration Science”, Unpublished Master's Thesis, Faculty of Law and Political Science, University of Mohamed Boudiaf, Msila.

- Maghribi, Abdel Hamid. (2008). Public Administration: Theory and Practice. Mansoura, College of Commerce.

- Staroňová, Katarína \& Gyorgy Gajduschek. (2016). “Public Administration Education in CEE Countries: Institutionalization of a Discipline", Policy and Society, 35, 4, pp. 351-370.

- Van der Waldt, G. (2014). “Public Administration Teaching and Interdisciplinary: Considering the Consequences", Teaching Public Administration, Vol. 32, (2), pp. 169-193. 
